Prof. dr Jurid Kolenc, pulkovnik, dipl. inž.

\section{Pokretna laboratorija za mjerenja u putnom saobraćaju}

\section{Uvod}

Sa mogućnošću primjene suvremenih metoda u rješavanju problema upravljanja vojnim putnim saobraćajem, došlo se do spoznaje o akutnom nedostatku adekvatnih parametara. Taj nedostatak, rezultat je, prvenstveno, neutvrđenog stanja svih zahtjevanih parametara, neadekvatno realizirane standardizacije, unifikacije i informatičke podrške u domeni osnovnih elemenata sistema putnog saobraćaja, kao što su: transportna sredstva, površine za kretanje, vozači i organizacija kao sistem, sa svim kompleksnim utjecajem mikro i makrookoline.

Postojeća rješenja, prvenstveno u domeni upravljanja vojnim putnim saobraćajem i kretanja uopce, a posebno vojnih motoriziranih kolona, uglavnom se zasnivaju na pravilskim odredbama i normama, koje, pak, nemaju i sve adekvatne parametre.

Za prikupljanje nedostajućih egzaktnih parametara u putnom saobracaju, danas u svijetu postoje razna rjesenja pokretnih laboratorija, koja, uglavnom, omogućuju:

- mjerenje parametara prohodnosti terena;

- mjerenje parametara vezanih za sistem vozilo-put;

- mjerenje parametara odvijanja saobraćajnog toka.
Određena parcijalna rješenja pokretnih Iaboratorija u našoj zemlji uglavnom omogućuju mjerenje određenih parametara puta i objekata na putu.

Imajući u vidu ovakvo stanje i potrebe, pristupilo se razvoju pokretne laboratorije za mjerenja u putnom saobraćaju, za dva osnovna cilja:

- mjerenje odgovarajućih parametara vojnog putnog saobraćaja za stvaranje banki podataka i dolaženja do potrebnih naučnih činjenica u okviru naučnoistraživačkog i nastavnog rada na Saobraćajnom smjeru Visokih vojnotehnickih škola KoV JNA;

- brzo prikupljanje i obrada odgovarajućih podataka o parametrima vojnog putnog saobraćaja, bitnih za donošenje optimalnih rješenja u oblasti kretanja vojnih motoriziranih kolona.

\section{Zahtjevi za razvojem pokretne laboratorije}

U skladu sa usvojenim ciljevima, utvrđeni su osnovni zahtjevi u pogledu eksploatacionih karakteristika i posebnih zahtjeva za mjerenje u vojnom putnom saobracaju.

Eksploatacione karakteristike pokretne laboratorije koje proizlaze iz naučnoistraživačkih i nastavnih zahtje- 
va, te specifičnosti vojnog putnog saobraćaja su:

- mogućnost mjerenja u pokretu i u mjestu;

- mogućnost kretanja u svim putnim, terenskim, vremenskim i vježbovnim uvjetima;

- mogućnost grupiranja mjerne i ostale opreme $\mathrm{u}$ odnosu na oblast i vrstu mjerenja;

- postojanje radnog prostora za četíri operatora;

- mogućnost stvaranja odgovarajućih mjernih lanaca i automatske obrade izmjerenih podataka;

- mogućnost stvaranja odgovarajuće mikroklime prema zahtjevima mjerne i ostale opreme, te rada operatora;

- autonomnost al pogledu napajanja naizmjeničnom električnom strujorn.

Posebni nastavni, naučnoistraživački i operativni zahtjevi, koje pokretna laboratorija ispunjava su:

a) prikupljanje podataka o površinamta za kretanje:

- elementi puta u situaciji, tilut:

- elementi puta u poprečnom pro-

-. elementi puta u uzdužnom profili,

- karakteristike i kvalitet kolničkog zastora,

- karakteristike i kvalitet objekata na putu,

- karakteristike i kvalitet opreme puta,

- karakteristike i prohodnost različitih vrsta terena, i sl.;

b) mjerenje eksploatacionih karakteristika vozila:

- potrošnja goriva motornih vozila u različitim uvjetima eksploatacije,

- karakteristike pojedinih sklopova motornih vozila, zavisno od uvjeta eksploatacije

- karakteristike ponašanja sklopa vozilo-teret u različitim uvjetima eksploatacije; c) mjerenje ergonomskih parametara u vojnom putnom saobraćaju:

- karakteristike mikroklime,

- karakteristike buke, vibracija, usporenja - ubrzanja i drugih sila,

- frekvencija pojave $i$ vrijeme trajanja pojedinih radnih aktivnosti,

- ergotehnički parametri elemenata mikro i makro-radnog mjesta vojnih vozača,

- energetske karakteristike rada u vojnom saobraćaju,

- senzomotorne karakteristike rada u vojnom saobraćaju,

- pouzdanost rada sistema covjek - stroj (vozac - vozilo),

- razina stecenih vještina i navika u radu vojnih vozača i saobraćajaca, i sl.;

d) mjerenje karakteristika saobraćaja na putnoj mreži:

- propusna moć karakteristiénih presjeka puta,

- gustina saobraćaja na karakteristiěnim dionicama puta,

- brzina kretanja na karakteristicnim uskim grlima,

— izmjeritelji kretanja vojnih motoriziranih kolona na karakteristicnim mjestima,

- detekcija i brojanje vozila na putu i sl.;

e) automatizacija procesa u saobraćaju:

- automatizirano prikupljanje i obrada odabranih podataka o ponašanju sistema vozač - vozilo - put sa kompleksnim utjecajem okoline $u$ realnim uvjetima,

- automatizirano planiranje vojnog saobraćaja na putevima $i$ provjera u praksi razrađenih fizičkih i simulacionih modela saobraćajnog toka,

- automatizirano upravljanje i kontrola vojnog putnog saobraćaja na putnoj mreži,

- automatizirano planiranje transporta u terenskim uvjetima i praktična provjera razrađenih modela maršrutizacije, 
- automatizirano prikupljanje, obrada i analiza podataka sa uviđaja saobraćajnih nezgoda, i sl.

\section{Razvoj pokretne laboratorije}

Nakon izrađene i usvojene prethodne analize i programa realizacije prišlo se razvoju pokretne laboratorije za mjerenja u putnom saobraćaju.

Razvoj je realiziran preko: zila,

- izbora osnovnog motornog vo-

— izbora odgovarajućeg kontejnera,

- spajanje motornog vozila i kontejnera uz odgovarajuće dorade, tejneru,

- izrade osnovne opreme u kon-

- izbora, nabavke i (ili) izrade, odgovarajuće laboratorijske opreme. nih Ianaca.

- stvaranje odgovarajućih mjer-

Osnovu laboratorije čini podvoz motornog vozila visoke pokretljivosti TAM $150 \mathrm{~T} 11 \mathrm{BV}$, formule pogona $6 \times 6$, spregnutog sa mobilnim kontejnerom K-30 (sl. 1).

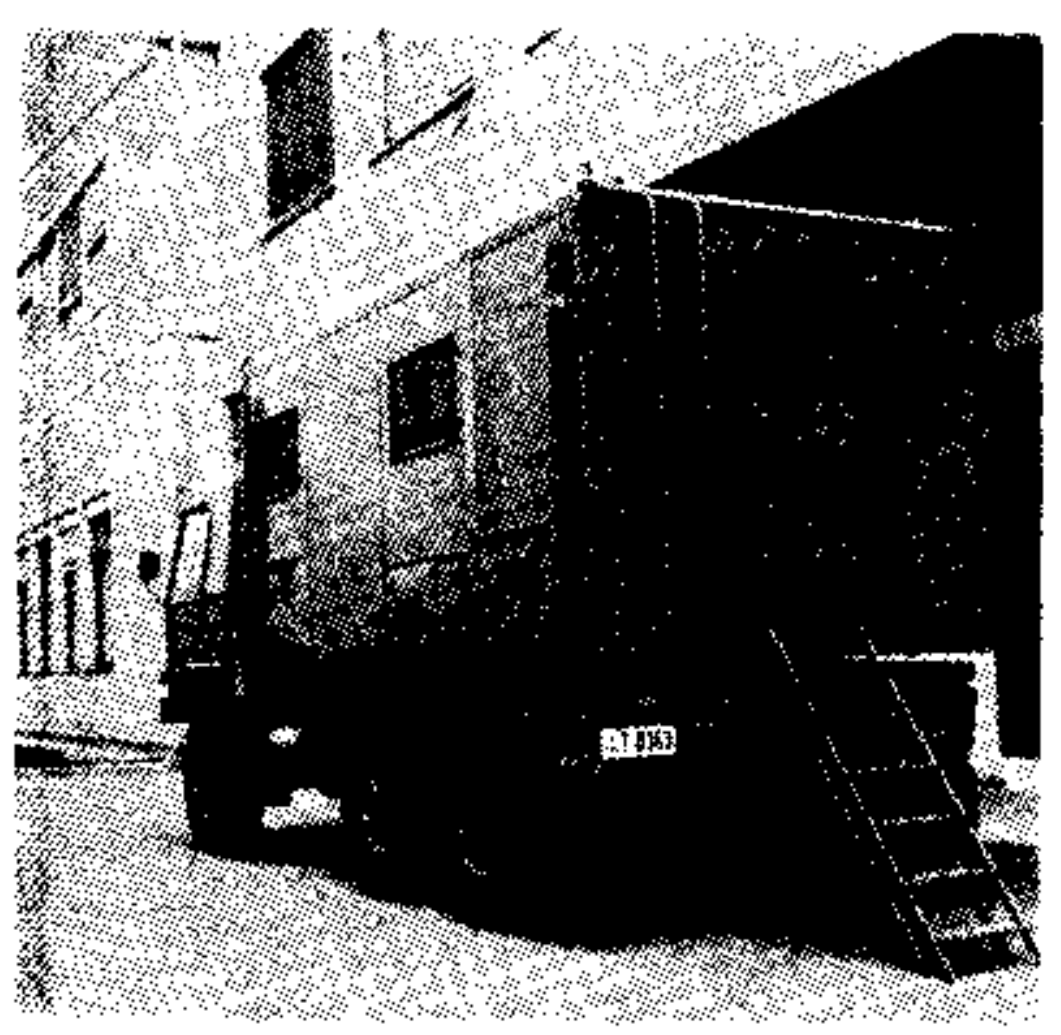

St. 1
Nadgradnju laboratorije čini osnovna oprema kontejnera $\mathrm{K}-30$, prilagođena za smještaj i korištenje odgovarajuce laboratorijske opreme i istovremeni rad cetiri operatora. Pored toga, obuhvaćena je i oprema i uređaji za stvaranje optimalne mikroklime za rad operatora i laboratorijske opreme, za proizvodnju näizmjenične električne struje, za rad u stacionarnim i pokretnim uvjetima i ostala pokretna oprema (sl, 2).

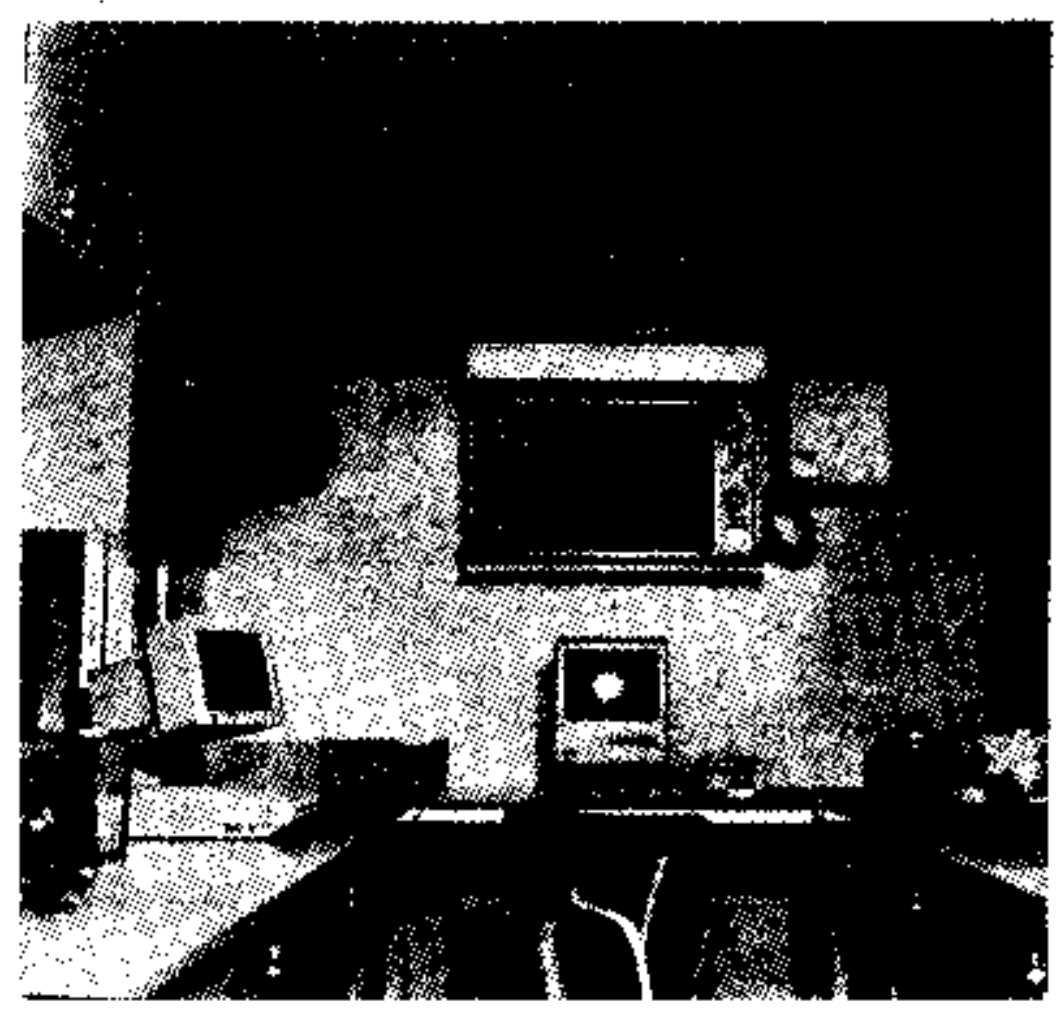

St. 2

Laboratorijska oprema je definirana, nabavijena i (ili) izrađena na osnovu postojećih inozemnih i domaćih spoznaja i iskustava, u skladu sa posebnim zahtjevima, koje pokretna laboratorija mora da ispuni.

Koncipiranje laboratorijske opreme izvršeno je fleksibilno, tako da se omoguéuje kontinuirano usavršavanje pokretne laboratorije u skladu sa narastanjem spoznaja o mogućnostima i razvoju nove laboratorijske opreme kod nas i u svijetu, kao i novim naučnoistraživačkim i nastavnim zahtjevima.

Laboratorija se u svojoj osnovi već nalazi na upotrebi za nastavne i naučnoistraživacke potrebe na Saobraćajnom smjeru Visokih vojnotehničkih škola KoV JNA. 
Osnovna laboratorijska oprema pokretne laboratorije, data u tabeli 1, djeIimično je smještena van kontejnera $\mathrm{K}-30$. Stvaranje odgovarajućih mjernih lanaca za potrebe nastavnog procesa sa četiri radria mjesta, odnosno za potrebe naučnoistraživačkog rada, vrši se kompletiranjem potrebne mjerne i ostale opreme za rad u stacionarnim uvjetima (si. 3), odnosno pokretnim uvjetima.

Tabela 1

Osnovna laboratorijska oprema pokretne laboratorije

\begin{tabular}{|c|c|c|}
\hline $\begin{array}{c}\text { Red. } \\
\text { br. }\end{array}$ & Vrsta mjerne opreme & $\begin{array}{c}\text { Ko- } \\
\text { mada }\end{array}$ \\
\hline 1 & 2 & 3 \\
\hline 1. & $\begin{array}{l}\text { Mobilna TV kamera sa mo- } \\
\text { gućnošću montiranja na od- } \\
\text { govarajuce dijelove kontej- } \\
\text { nera K-30 i kabine motor- } \\
\text { nog vozila }\end{array}$ & 1 \\
\hline 2. & $\begin{array}{l}\text { Radarski komplet za mjere- } \\
\text { nje brzine kretanja }\end{array}$ & 1 \\
\hline 3. & $\begin{array}{l}\text { Komplet uretaja za detek- } \\
\text { ciju i brojanje vozila }\end{array}$ & 1 \\
\hline
\end{tabular}

\begin{tabular}{|c|c|c|}
\hline 1 & 2 & 3 \\
\hline 4. & $\begin{array}{l}\text { Komplet uređaja za vršenje } \\
\text { uviđaja saobraćajnił nezgo- } \\
\text { da }\end{array}$ & 1 \\
\hline 5. & $\begin{array}{l}\text { Komplet pokretrih daljin- } \\
\text { sko-upravljačkih semafora }\end{array}$ & 1 \\
\hline 6. & $\begin{array}{l}\text { Komplet uredaja za mjere- } \\
\text { nje buke i vibracija }\end{array}$ & 1 \\
\hline 7. & $\begin{array}{l}\text { Komplet uređaja za mjere- } \\
\text { nje termickog komfora rad- } \\
\text { nog mjesta vozača }\end{array}$ & 1 \\
\hline 8. & $\begin{array}{l}\text { Komplet uređaja za mjere- } \\
\text { nje mikroklime radnog mje- } \\
\text { sta vozač }\end{array}$ & 1 \\
\hline 9. & $\begin{array}{l}\text { Komplet uredaja za mjere- } \\
\text { nje kožno-električnih reak- } \\
\text { cija vozača pri upravljanju } \\
\text { vozilom }\end{array}$ & 1 \\
\hline 10. & $\begin{array}{l}\text { Komplet uredaja za mjere- } \\
\text { nje energetske potrosnje čo- } \\
\text { vjeka pri radu u saobraćaju } \\
\text { i transportu }\end{array}$ & 1 \\
\hline 11. & $\begin{array}{l}\text { Komplet uredaja za mjere- } \\
\text { nje svjetlosnog bljeska i } \\
\text { kontrasta svjetlosti }\end{array}$ & 1 \\
\hline 12. & $\begin{array}{l}\text { Komplet uredaja za mjere- } \\
\text { nje zagađenosti mikrookoli- } \\
\text { ne radnog mjesta }\end{array}$ & 1 \\
\hline 13. & $\begin{array}{l}\text { Prijenosni saobracajni znaci } \\
\text { i čunjevi za reguliranje sao- } \\
\text { bracaja }\end{array}$ & 10 \\
\hline
\end{tabular}

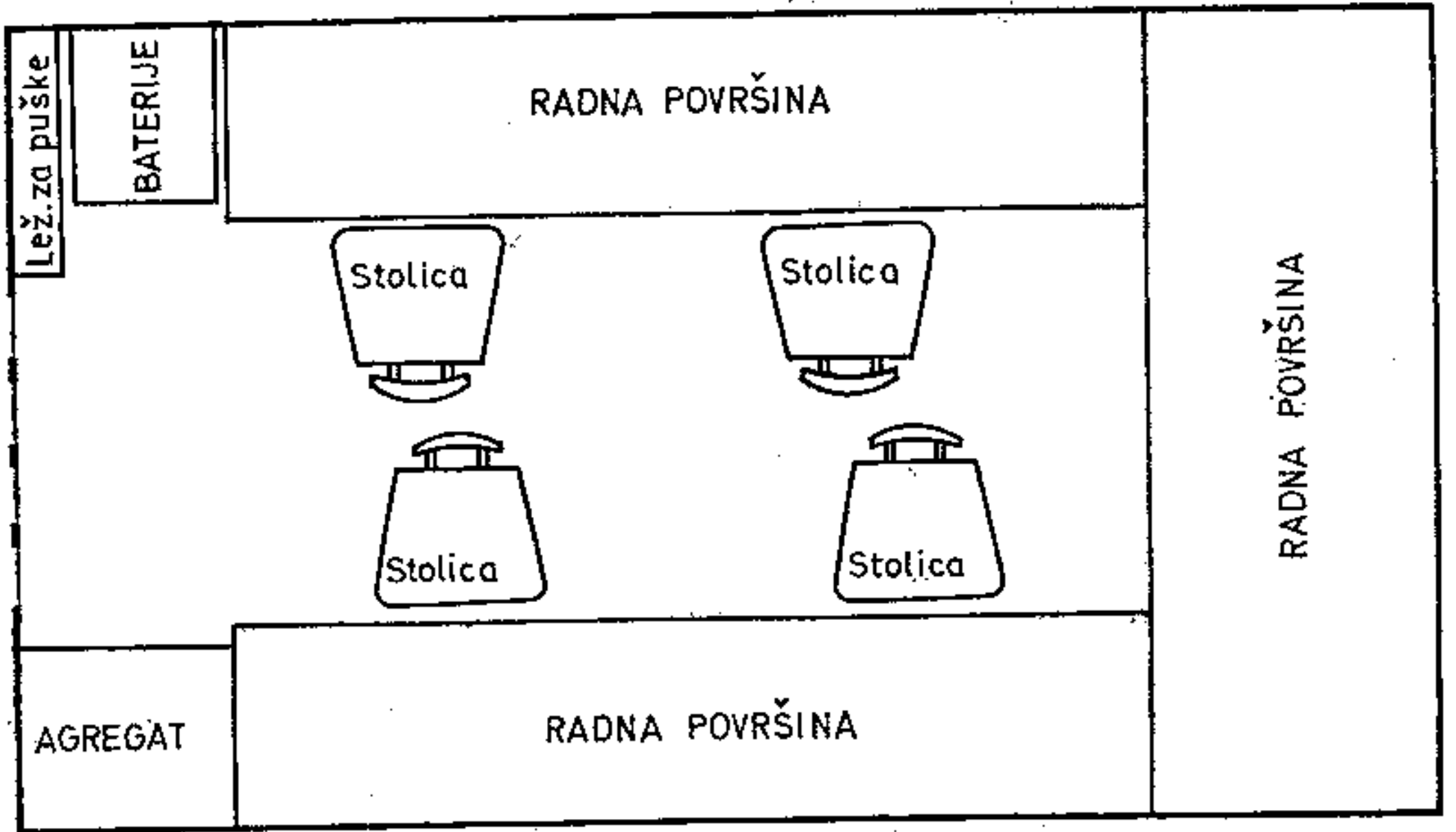

Si. 3 


\begin{tabular}{|c|c|c|}
\hline 14. & $\begin{array}{l}\text { Komplet opreme za reguli- } \\
\text { ranje i kontrolu putnog sao- } \\
\text { braćja }\end{array}$ & $\mathbf{1}$ \\
\hline 15. & $\begin{array}{l}\text { Prijenosni penetrometar, } \\
\text { mali }\end{array}$ & 1 \\
\hline 16. & $\begin{array}{l}\text { Komplet mjernih uredaja za } \\
\text { mjerenje stanja puta i tere- } \\
\text { na }\end{array}$ & 1 \\
\hline 17. & $\begin{array}{l}\text { Uređaj za mjerenje nad- } \\
\text { morske visine }\end{array}$ & I \\
\hline 18. & $\begin{array}{l}\text { Uređaj za osvjetljenje oko- } \\
\text { line (top reflektor) }\end{array}$ & 1 \\
\hline 19. & Teodolit & 1 \\
\hline 20. & Nivelir & 1 \\
\hline 21. & Trasirke & 12 \\
\hline 22. & Padomjer & 1 \\
\hline 23. & Z̈irokompas & I \\
\hline 24. & $\begin{array}{l}\text { Laserski i akusticki dalji- } \\
\text { nomjer }\end{array}$ & 2 \\
\hline 25. & $\begin{array}{l}\text { Komplet uređaja za mjere- } \\
\text { nje osovinskog pritiska vo- } \\
\text { zila }\end{array}$ & 1 \\
\hline 26. & $\begin{array}{l}\text { Uređaj za mjerenje slobod- } \\
\text { nog hoda tocka upravljaと̌a }\end{array}$ & 1 \\
\hline 27. & $\begin{array}{l}\text { Mjerac temperature smrza- } \\
\text { vanja antifriza }\end{array}$ & 1 \\
\hline 28. & $\begin{array}{l}\text { Mjerač gustine elektrolita } \mathfrak{u} \\
\text { akumulatoru }\end{array}$ & 1 \\
\hline 29. & Mjerač napona akumulatora & 1 \\
\hline 30. & $\begin{array}{l}\text { Mjerac dubine sara protek- } \\
\text { tora pneumatika }\end{array}$ & 1 \\
\hline 31. & Komplet »peti toxakк & 1 \\
\hline 32. & $\begin{array}{l}\text { Uređaj za mjerenje potros- } \\
\text { nje goriva kod otto motora }\end{array}$ & 1 \\
\hline 33. & $\begin{array}{l}\text { Uredaj za mjerenje potros- } \\
\text { nje goriva kod dizel motora }\end{array}$ & 1 \\
\hline 34. & $\begin{array}{l}\text { Uređaj za mjeremje karak- } \\
\text { teristika ispusnih plinova } \\
\text { dizel motora }\end{array}$ & 1 \\
\hline 35. & $\begin{array}{l}\text { Uređaj za mjerenje karak- } \\
\text { teristika ispusnih plinova } \\
\text { otto motora }\end{array}$ & 1 \\
\hline 36. & $\begin{array}{l}\text { Mjerač ubrzanja - uspore- } \\
\text { nja motornog vozila }\end{array}$ & 1 \\
\hline 37. & $\begin{array}{l}\text { Radio-uređaj prenosni UKT } \\
\text {-FM } 66 / 13\end{array}$ & 4 \\
\hline 38. & $\begin{array}{l}\text { Radio-uređaj prenosni RU- } \\
-12\end{array}$ & 1 \\
\hline
\end{tabular}

\begin{tabular}{|l|l|c|}
\hline 39. & $\begin{array}{l}\text { Durbinski periskop sa pove- } \\
\text { ćanjem 10x tip ADM-58 }\end{array}$ & 1 \\
\hline 40. & Mikroracunari & 4 \\
\hline 41. & Printer wImage writers & 1 \\
\hline 42. & $\begin{array}{l}\text { Pretvarači analognih u digi- } \\
\text { talne signale komunika- } \\
\text { cijski interface }\end{array}$ & 4 \\
\hline 43. & Videoricorder & 1 \\
\hline 44. & Portabl TV color & 1 \\
\hline
\end{tabular}

Napomena: uz osnovnu mjernu opremu, postoji jos znatna oprema za stvaranje odgovarajuctín mjernih lanaca, rad u stacionarnim ili pokretnim uvjetima, i sl.

\section{Zaključak}

Prezentirani zahtjevi za razvojem pokretne laboratorije za mjerenja $u$ putnom saobraćaju, kao i sam razvoj njene osnove, nadgradnje, te laboratorijske i druge opreme, svim zainteresiranim u JNA omogućuju stjecanje uvida u njenu namjenu i mogućnosti.

Problem metoda mjerenja $i$ ispunjavanja posebnih nastavnih, naučnoistraživačkih i operativnih zahtjeva pokretne laboratorije, u ovom radu nije razmatran. Složenost pojedinih metoda mjerenja, uz primjenu pojedinačnih uređaja ili mjernih lanaca, iziskuje potrebu posebne obrade, što ce se nastojati učiniti u više posebnih clanaka u narednom periodu. Pored toga, prezentirati će se i dobijeni rezultati konkretnih mjerenja.

Ovakvim pristupom, nadamo se, u narednom dugoročnom periodu, $u$ ovoj domeni, može se očekivati znatnije obogaćenje teorije $i$ prakse vojnog putnog saobraćaja, egzaktnim naučnim cinjenicama, a samim tim i praćenje ukupne efikasnosti njegovog funkcioniranja. 